Article

\title{
Bark Extract of the Amazonian Tree Endopleura uchi (Humiriaceae) Extends Lifespan and Enhances Stress Resistance in Caenorhabditis elegans
}

\author{
Herbenya Peixoto ${ }^{1}$ D, Mariana Roxo ${ }^{1}$, Emerson Silva ${ }^{2}$, Karla Valente ${ }^{2}$, Markus Braun ${ }^{1}$, \\ Xiaojuan Wang ${ }^{1}$ (D) and Michael Wink ${ }^{1, * \mathbb{D}}$ \\ 1 Institute of Pharmacy and Molecular Biotechnology, Heidelberg University, INF 364, \\ D-69120 Heidelberg, Germany; hspeixoto1@gmail.com (H.P.); marianaroxocorreia@gmail.com (M.R.); \\ markus.braun@gmx.ch (M.B.); wxjsz@hotmail.com (X.W.) \\ 2 Faculty of Pharmaceutical Science, Federal University of Amazonas (UFAM), 6200 General Rodrigo, \\ Manaus 69077-000, Brazil; eslima75@gmail.com (E.S.); karlaacussena@gmail.com (K.V.) \\ * Correspondence: wink@uni-heidelberg.de; Tel.: +49-62-2154-4880
}

Academic Editors: Lillian Barros and Isabel C.F.R. Ferreira

Received: 6 February 2019; Accepted: 1 March 2019; Published: 6 March 2019

\begin{abstract}
Endopleura uchi (Huber) Cuatrec (Humiriaceae), known as uxi or uxi-amarelo in Brazil, is an endemic tree of the Amazon forest. In traditional medicine, its stem bark is used to treat a variety of health disorders, including cancer, diabetes, arthritis, uterine inflammation, and gynecological infections. According to HPLC analysis, the main constituent of the bark extract is the polyphenol bergenin. In the current study, we demonstrate by in vitro and in vivo experiments the antioxidant potential of a water extract from the stem bark of $E$. uchi. When tested in the model organism Caenorhabditis elegans, the extract enhanced stress resistance via the DAF-16/FOXO pathway. Additionally, the extract promoted an increase in the lifespan of the worms independent from caloric restriction. It also attenuated the age-related muscle function decline and formation of polyQ40 plaques, as a model for Huntington's disease. Thus, these data support anti-aging and anti-oxidant properties of E. uchi, which has not yet been described. More studies are needed to assess the real benefits of E. uchi bark for human health and its toxicological profile.
\end{abstract}

Keywords: Caenorhabditis elegans; antioxidants; bergenin; stress resistance; lifespan; Huntington; uxi; Endopleura uchi

\section{Introduction}

Endopleura uchi (Huber) Cuatrec, popularly known in Brazil as uxi or uxi-amarelo, is an endemic tree found throughout the entire Brazilian part of the Amazon basin [1]. The species belongs to the family Humiriaceae and is the only member of its genus. This valuable tree is locally used for its wood, bark, fruit, and seeds [2].

Traditional medicinal applications of the stem bark of E. uchi include the treatment and prevention of cancer, diabetes, high cholesterol, arthritis, diarrhea, and genitourinary disorders, especially uterine inflammations and infections [3]. A recent ethnobotanical survey has reported a high demand for uxi bark in regional markets due to its popular therapeutic claims [4-7]. However, few studies have investigated the bioactivities of E. uchi.

Silva and Teixeira [8] reported the in vitro antioxidant and antibacterial activity of the bark, as well as inhibition of cholinesterase (AChE, BuChE) and $\alpha$-glucosidase. The authors associated the inhibition of $\alpha$-glucosidase with the traditional use of the bark to treat diabetes. Additionally, no cytotoxic effect was observed when tested in human colorectal adenocarcinoma cells (Caco-2). When tested in HeLa 
cells, a polysaccharide fraction of E. uchi barks significantly reduced proliferation and cell viability [9]. Sá et al. [10] demonstrated that the subchronic administration of E. uchi bark extract has no toxic effects on male and female Wistar rats. Politi et al. [11] also assessed the safety profile of E. uchi bark and reported the absence of oral acute toxicity.

Previous phytochemical investigations of E. uchi bark have revealed the presence of tannins, terpenoids (saponins and steroids), and coumarins [12-14]. The isocumeric secondary metabolite bergenin has been reported by several researchers as the major compound in E. uchi bark [8,15-17].

In the current study, we investigated a water extract from the stem bark of E. uchi regarding its potential antioxidant and anti-aging properties using the nematode Caenorhabditis elegans as an experimental model, which is widely used in this context.

\section{Material and Methods}

\subsection{Plant Material and Extract}

Endopleura uchi extract (EU) was obtained from stem bark purchased from a local trader in Manaus-AM (Brazil). The bark material was weighed, milled, and exhaustively extracted with distilled water $(5 \times 1 \mathrm{~L})$ at room temperature during an overall extraction period of 5 days. Using a rotary evaporator, the water extract was concentrated at low pressure at $40^{\circ} \mathrm{C}$, frozen at $-80^{\circ} \mathrm{C}$, and finally lyophilized to obtain a fine dried powder. The plant material used in this study is deposited in the sample collection of IPMB (Institut für Pharmazie und Molekulare Biotechnologie, Heidelberg, Germany) under the accession number IPMB P8636.

\subsection{Antioxidant Activity}

In a 96-well microplate, $100 \mu \mathrm{L}$ of sample were added to $100 \mu \mathrm{L}$ of $200 \mu \mathrm{M}$ DPPH. After $30 \mathrm{~min}$, the absorbance was measured in a microplate reader (Tecan Trading AG, Männedorf, Switzerland) at $517 \mathrm{~nm}$ [18]. All measurements were performed in triplicate. The $\mathrm{EC}_{50}$ is presented in $\mu \mathrm{g} / \mathrm{mL}$.

\subsection{Total Phenolic Content}

In a 96-well microplate, $20 \mu \mathrm{L}$ of sample were added to $100 \mu \mathrm{L}$ of Folin-Ciocalteu reagent; after $5 \mathrm{~min}, 80 \mu \mathrm{L}$ of sodium carbonate $(7.5 \%$ solution) were added to the wells. The reaction ran for $2 \mathrm{~h}$ protected from the light and at room temperature; the absorbance was measured at $750 \mathrm{~nm}$. The assay was carried out in triplicate and repeated three times. The phenolic content is expressed as gallic acid equivalents (GAE/g of sample).

\subsection{Chemical Characterization and Quantification of Bergenin}

Bergenin content of the uchi extract was determined by high performance liquid chromatography (HPLC) in a Shimadzu Proeminence Chromatograph with a UV-Vis detector SPD-10A. The method used was adapted from Tacon and Nunomura $[17,19]$. The chromatography was run in gradient mode with methanol: formic acid $0.1 \%$ as the mobile phase $\mathrm{A}$, and aqueous formic acid $0.1 \%$ as the mobile phase B. The column C-18 SphereClone $5 \mu$ ODS $(150 \times 4.60 \mathrm{~mm}$ and particle size $5 \mu \mathrm{m})$ and the detector was set to wavelength of $272 \mathrm{~nm}$. The flow rate of the mobile phase was $0.8 \mathrm{~mL} / \mathrm{min}$. The calibration curve was constructed using bergenin (Sigma, St Louis, MO, USA), ranging from 0.04 to $1.5 \mathrm{mg} / \mathrm{mL}$, obtaining a linear correlation coefficient of 0.9995 .

\subsection{C. elegans Strains and Maintenance}

The worms were cultivated on NGM plates inoculated with living E. coli OP50 as food source and incubated at $20^{\circ} \mathrm{C}$, except when mentioned. For the current work we used the strains N2 (wt), CF1038 (daf-16(mu86)), GR1307 (daf-16(mgDf50)), CF1553 (muIs84 [(pAD76) sod-3p::GFP + rol-6]), AM141 (rmIs133[P(unc-54)Q40::YFP]), TJ375 (gpIs1[hsp-16-2::GFP]), and BA17 [fem-1(hc17) IV)]. 
Age synchronous cultures were obtained by treating the adult hermaphrodites with a lysis solution ( $5 \mathrm{M} \mathrm{NaOH}$ and $5 \% \mathrm{NaOCl}$ ) for $5 \mathrm{~min}$ and separating the eggs from the debris by density gradient centrifugation using $60 \%$ sucrose solution [20]. The collected eggs were allowed to hatch in M9 buffer [21].

\subsection{Survival Assay under Oxidative Stress}

For this assay, age synchronized L1 larvae (N2, CF1038, and GR1307 strains) were grown in $S$-medium. The larvae were sorted into groups of 75 individuals and treated with the extract for $48 \mathrm{~h}$. Subsequently, $80 \mu \mathrm{M}$ of the pro-oxidant juglone (5-hydroxy-1,4-naphthalenedione) were added to each group and $24 \mathrm{~h}$ later the number of live and dead worms were scored. We considered a worm to be dead when it did not respond to a gentle touch with a platinum wire [20]. The assay was carried out in triplicate and is presented as mean \pm SEM compared by one-way ANOVA followed by Bonferroni (post-hoc).

\subsection{Intracellular ROS Accumulation}

For this assay, we used age synchronized L1 larvae (N2 strain) grown in S-medium. The larvae were sorted into groups and treated with the extract for $48 \mathrm{~h}$. Subsequently, the ROS-sensitive fluorescent dye H2DCFDA $(50 \mu \mathrm{M})$ was added to each group. The staining took $1 \mathrm{~h}$, protected from the light, at $20^{\circ} \mathrm{C}$; afterwards the worms were mounted onto a glass slide and paralyzed with a drop of $10 \mathrm{mM}$ sodium azide. Using a BIOREVO BZ-9000 fluorescence microscope (Keyence Deutschland $\mathrm{GmbH}$, Neu-Isenburg, Germany), live images of at least 30 worms per group were captured with an excitation filter set to $480 / 20 \mathrm{~nm}$ and emission filter set to $510 / 38 \mathrm{~nm}$ [20]. The relative fluorescence was determined densitometrically using the software Image J (National Institute of Health, Bethesda, Bethesda, MD, USA). The results are presented as mean fluorescence intensity (mean \pm SEM) and compared by one-way ANOVA followed by Bonferroni (post-hoc). The assay was repeated three times.

\subsection{Quantification of Gene Expression Using GFP Reporter}

For this assay, we used age-synchronized worms grown in S-medium. To evaluate sod-3:GFP expression, L1 larvae (CF1553 strain) were treated with the extract for $48 \mathrm{~h}$ and analyzed under a fluorescence microscope, as described above. To evaluate $h s p-16.2:: G F P$ expression, L4 larvae (TJ375 strain) were treated with the extract for $48 \mathrm{~h}$ and subsequently exposed to $20 \mu \mathrm{M}$ juglone; $24 \mathrm{~h}$ later, the worms were analyzed by fluorescence microcopy, as described. The assays were repeated three times and the results are presented as fluorescence intensity (mean $\pm \mathrm{SEM}$ ) compared by one-way ANOVA followed by Bonferroni (post-hoc).

\subsection{Longevity Assay}

For this assay, we used age-synchronized worms at day 1 of adulthood (BA17 strain) grown in S-medium. The adults were treated with the extract, except the control group. Throughout the entire period of observation, the worms were incubated at $25{ }^{\circ} \mathrm{C}$ and transferred every second day to fresh medium supplemented with extract following their treatment groups. Dead worms were scored during the transfer and removed from the assay. Worms exhibiting extruded gonads or internally hatched progeny were scored as censored and removed from the assay. We considered a worm to be dead when it did not respond to a gentle touch with a platinum wire [22]. The assay was repeated three times and the results are presented as percentage of survival. The statistical significance was determined by Log-rank (Mantel-Cox) tests followed by Gehan-Breslow-Wilcoxon Test.

\subsection{Quantification of PolyQ40::GFP Aggregate Formation}

For this assay, we used age synchronized L1 larvae (AM141 strain) grown in S-medium. This strain serves as a model for Huntington disease. The larvae were treated with the extract for $48 \mathrm{~h}$ and 
subsequently submitted to fluorescence microscopy, as described above [22]. The results are presented as number of PolyQ40::GFP aggregates (mean \pm SEM) and compared by one-way ANOVA followed by Bonferroni (post-hoc).

\subsection{Pharyngeal Pumping Rate}

For this assay, we used age synchronized worms (N2 strain) grown on NGM agar plates. The adult worms were daily transferred to fresh plates, supplemented following their treatment groups, throughout the entire reproductive period. At day 5 and day 10 of adulthood, the worms were observed under a stereomicroscope for $1 \mathrm{~min}$ to score the pumping activity of the pharynx, which can serve as a measure for muscle impairment during aging [23]. The results are presented as pumps/min (mean \pm SEM) and compared by two-way ANOVA followed by Bonferroni (post-hoc).

\subsection{Body Length}

If C. elegans is kept under dietary restriction (DR), its body length will decrease. To assess the body length, age synchronized L4 larvae (N2 strain) were treated with the extract for $24 \mathrm{~h}$; subsequently, the worms were mounted onto a glass slide and submitted to bright field microscopy. Live images were taken from at least 30 worms per group; the length was measured from head to tail using the software ImageJ (version 1.48, National Institute of Health, Bethesda, MD, USA). The results are presented as body length in $\mu \mathrm{m}$ (mean \pm SEM) and compared by one-way ANOVA followed by Bonferroni (post-hoc).

\subsection{Antimicrobial Activity}

Susceptibility of Escherichia coli strain OP50 to the extracts was assessed by means of well diffusion test according to CLSI (2014) with slight modifications [24]. Briefly, bacteria were grown on Müller-Hinton agar (MHA) and the cell suspension was adjusted to $0.5 \mathrm{McFarland}$ standard. Wells with $6 \mathrm{~mm}$ in diameter were punched out and loaded with $70 \mu \mathrm{L}$ of $10 \mathrm{mg} / \mathrm{mL}$ sample dissolved in sterile water. Ampicillin and ciprofloxacin $(256 \mu \mathrm{g} / \mathrm{mL})$ were used as positive controls. Diameters of the zones of inhibition (ZI) were assessed $24 \mathrm{~h}$ after incubation at $35^{\circ} \mathrm{C}$. The assay was repeated three times. The bacteria were purchased from the Caenorhabditis Genetics Center (CGC, University of Minnesota, Minneapolis, MN, USA).

\section{Results}

\subsection{Antioxidant Activity in Vitro and Chemical Characterization of the Bark Extract}

The bark extract obtained from E. uchi showed an antioxidant capacity in vitro as powerful as standard dietary antioxidants, such as vitamin C and EGCG, when tested in DPPH assay (Table 1). Correspondingly, a high content of phenolics was observed using Folin-Ciocalteu method (850 GAE/g extract). Through HPLC, the isocoumeric bergenin was found to be the major compound in the extract $(4.5 \mathrm{~g} / 100 \mathrm{~g}$ of dry extract; Figure 1$)$.

Table 1. Antioxidant activity of Endopleura uchi (EU) assessed by DPPH assay.

\begin{tabular}{cc}
\hline SAMPLE & EC50 $(\mu \mathrm{G} / \mathrm{ML})$ \\
\hline EU & 8.0 \\
EGCG & 1.2 \\
VITAMIN C & 2.1 \\
\hline
\end{tabular}



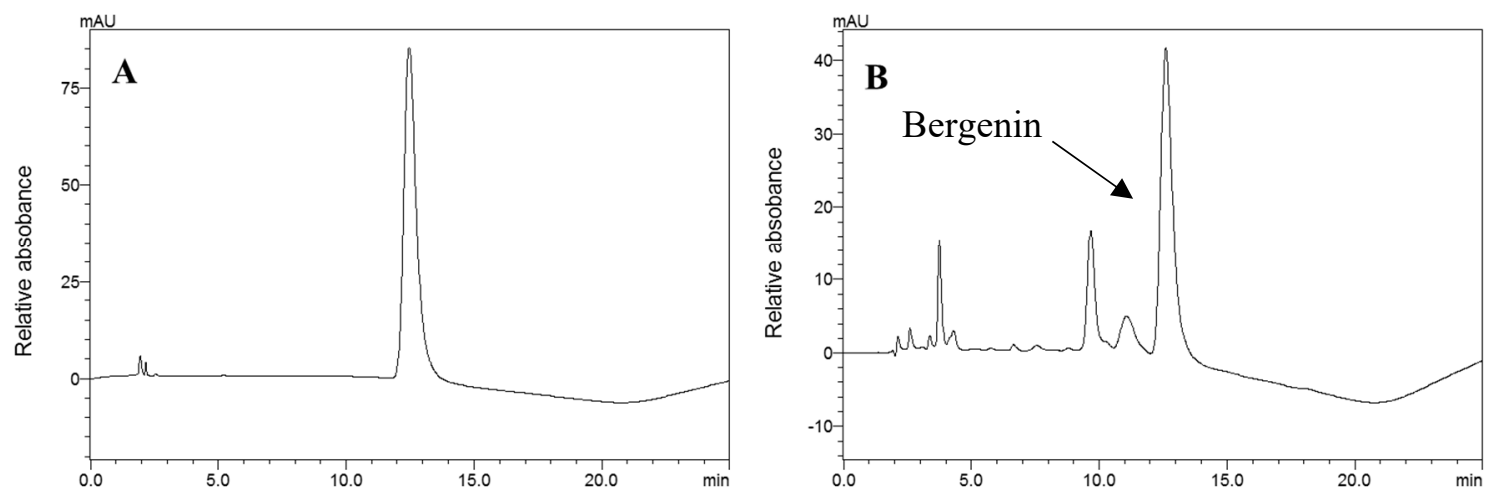

Figure 1. HPLC profile of the bergenin standard (A) and the aqueous bark Endopleura uchi extract (B) analyzed at $272 \mathrm{~nm}$.

\subsection{Effect of the Extract on Intracellular ROS Accumulation}

Endogenous intracellular ROS production was investigated in wild type (N2 (wt)) worms under stress-free conditions. The result obtained indicated a significant decrease in ROS accumulation among worms treated with the EU as compared with the untreated control group. The decrease was up to $80 \%$ when the worms were treated with $200 \mu \mathrm{g} / \mathrm{mL}$ EU (adjusted $p$-value < 0.0001; Figure 2).

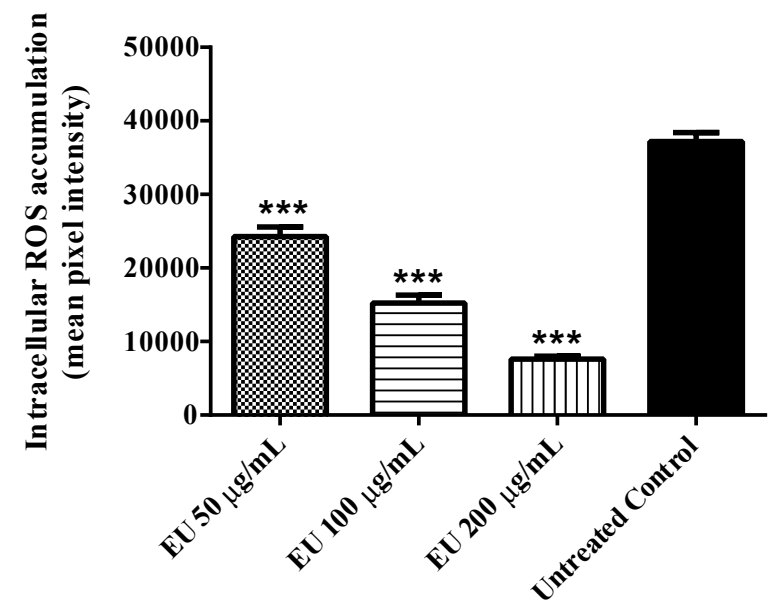

Figure 2. Quantification of intracellular ROS in N2 worms using DCFDA after treatment with Endopleura uchi extract (EU). Worms treated with EU showed lower levels of ROS compared to the control group. Data are presented as mean pixel intensity \pm SEM $(n=40$, replicated 3 times). *** $p<0.001$, compared to the untreated control by one-way ANOVA followed by Bonferroni (post-hoc).

\subsection{Protection against Oxidative Stress}

Protection of the worms against oxidative stress by the extract was assessed by comparing the survival rate of wild type worms (N2 (wt)) after juglone-induced oxidative stress. The results indicated a significant higher survival rate among EU treated worms. At the highest tested concentration $(200 \mu \mathrm{g} / \mathrm{mL}$ EU), $77 \%$ of the worms remained alive after juglone exposure compared to $27 \%$ scored in the extract-free group (adjusted $p$-value $=0.0017$; Figure 3a).

In order to find out if DAF16-FOXO pathway plays a role in the stress resistance observed after EU treatment, we performed the same protocol using mutant strains, in which DAF16 was inactivated (strains: CF1038 (daf-16(mu86)I) and GR1307 (daf-16(mgDf50)). As illustrated in Figure 3b,c, these mutants did not benefit from the antioxidant properties of EU as did the wild type worms (N2 (wt)). 


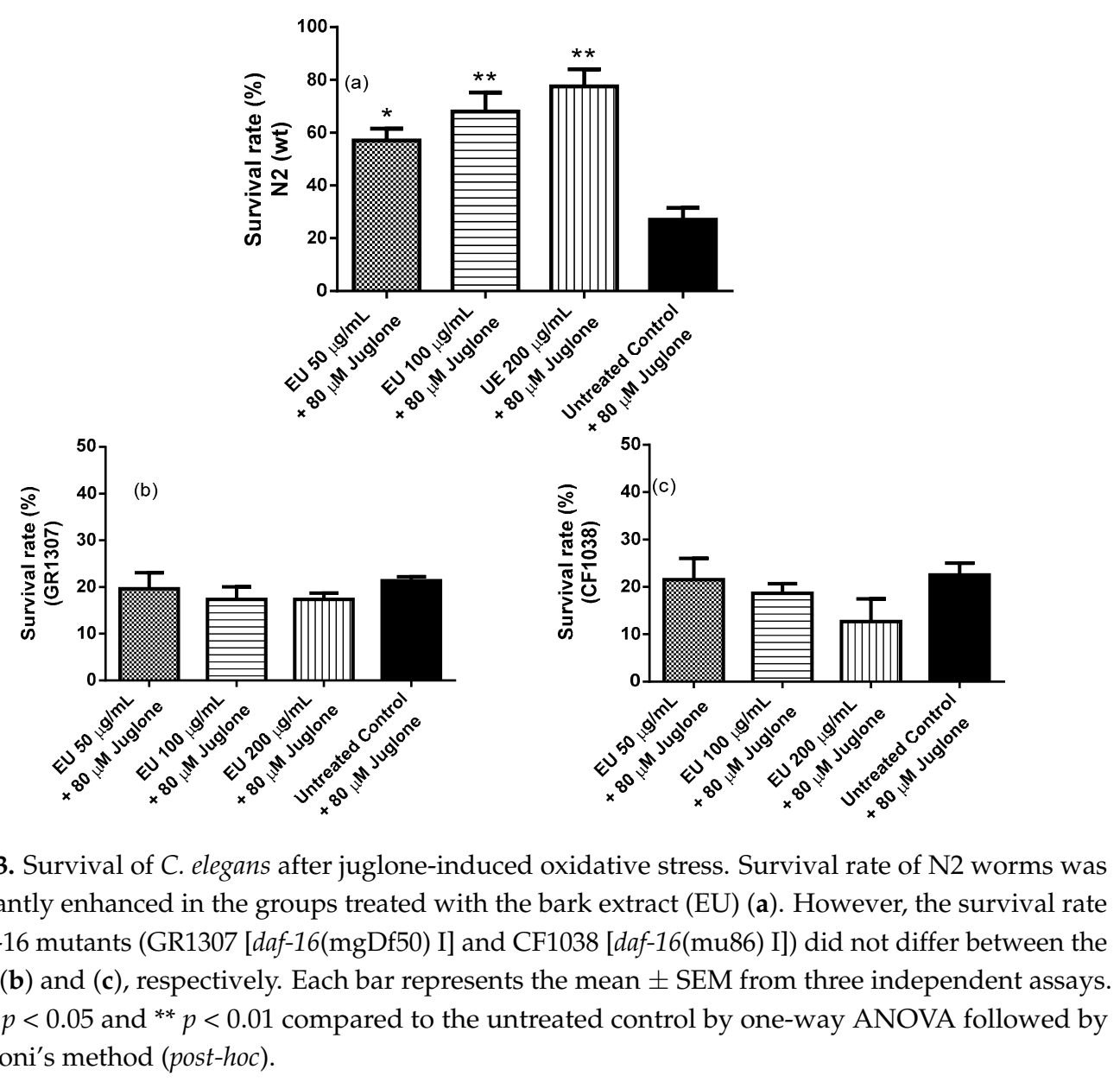

\subsection{Effect of the Extract on the Expression of Stress Response Genes (hsp-16.2::GFP and sod-3::GFP)}

The expression of sod-3 was investigated using mutant worms (strain CF1553), in which sod-3 has been fused with a GFP reporter. From analyses of the emitted fluorescence, we observed a significant increase in sod-3::GFP expression by $44 \%$ among EU treated worms compared with the untreated control group (adjusted $p$-value $<0.0001$; Figure 4a).

The expression of $h s p-16.2$ was assessed using the mutant strain TJ375, in which $h s p-16.2$ is fused with GFP. After mild oxidative stress, induced by adding a low concentration of juglone to the medium, we observed a significant fluorescence in the nematodes. The intensity was reduced among EU treated worms as compared with untreated worms. The decrease was up $40 \%$ at a concentration of $200 \mu \mathrm{g} / \mathrm{mL}$ EU (adjusted $p$-value < 0.0001; Figure $4 \mathrm{~b}$ ).

\subsection{Effect of the Extract on Longevity}

A long-term assay was performed to test whether EU can influence longevity in C. elegans. The results obtained indicated extension of lifespan by 33\% among BA17 worms treated with EU as compared to untreated control group ( $p$-value $p<0.0001$; Figure $5 a$ ). However, when the assay was performed with the daf-16 null mutants (CF1038 strain) no significant difference in the mean lifespan was observed between treated and untreated worms (Figure $5 b$ ), indicating that the transcription factor DAF16 plays a role in this context.

\subsection{Effect of the Extract on the Pharyngeal Pumping Rate}

During aging, muscle activity is impaired. As a marker for muscle activity, the pharyngeal pumping activity can be monitored in C. elegans. The pumping activity of the pharynx was scored in wild type (N2 (wt)) worms at day 5 and 10 of adulthood and revealed a significant difference among 
the groups. Worms cultured in medium supplemented with EU exhibited an improved pumping function of the pharynx. At day 10, the pumping rate among EU treated worms was $128 \%$ higher than that scored among untreated worms ( $p$-value $<0.01$; Figure 6 ). The data indicates that the muscle function is better preserved in worms under EU treatment as they age. Such a result also indicates that EU treated worms did not starve during their lifetime, so caloric restriction effect can be ruled out.

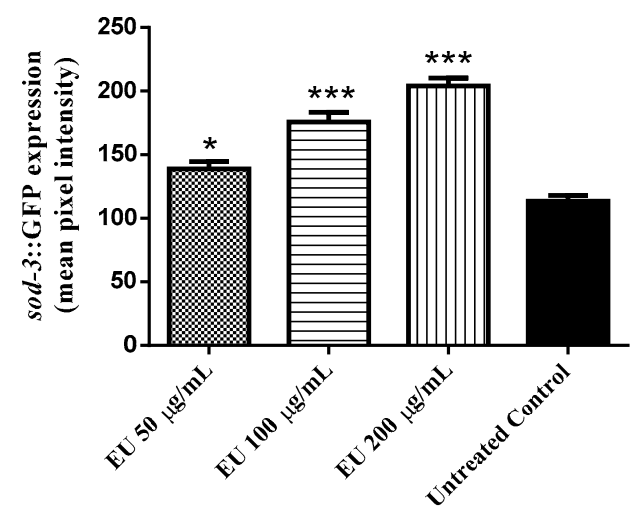

(a)

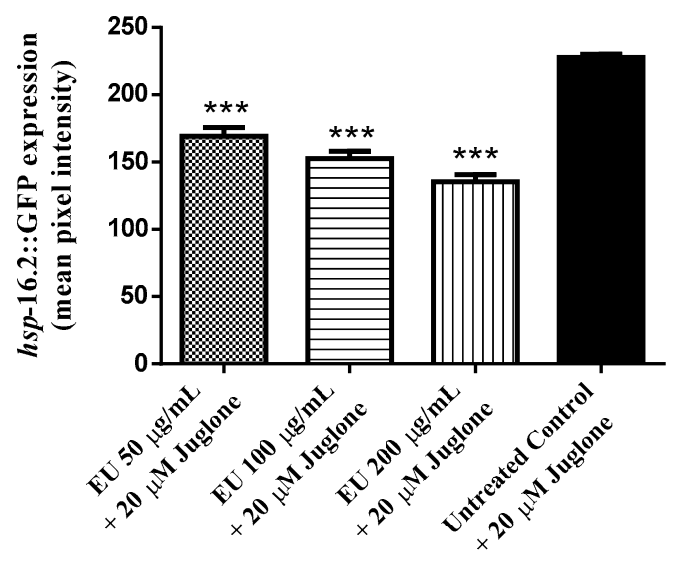

(b)

Figure 4. Expression of stress response genes. CF1553 worms [(pAD76)sod-3p::GFP + rol-6] treated with Endopleura uchi (EU) showed significant higher levels of SOD-3::GFP compared to the untreated control group (a), and mutant worms TJ375 [hsp-16.2::GFP(gplsI)] exposed to $20 \mu \mathrm{M}$ juglone presented significant lower levels of HSP-16.2::GFP when compared with the untreated control worms similarly exposed to $20 \mu \mathrm{M}$ juglone (b). Data are presented as mean pixel intensity (mean $\pm \mathrm{SEM}$ ) from three independent experiments. Note: ${ }^{*} p<0.05$ and ${ }^{* * *} p<0.001$ related to the control, analyzed by one-way ANOVA followed by Bonferroni (post-hoc).
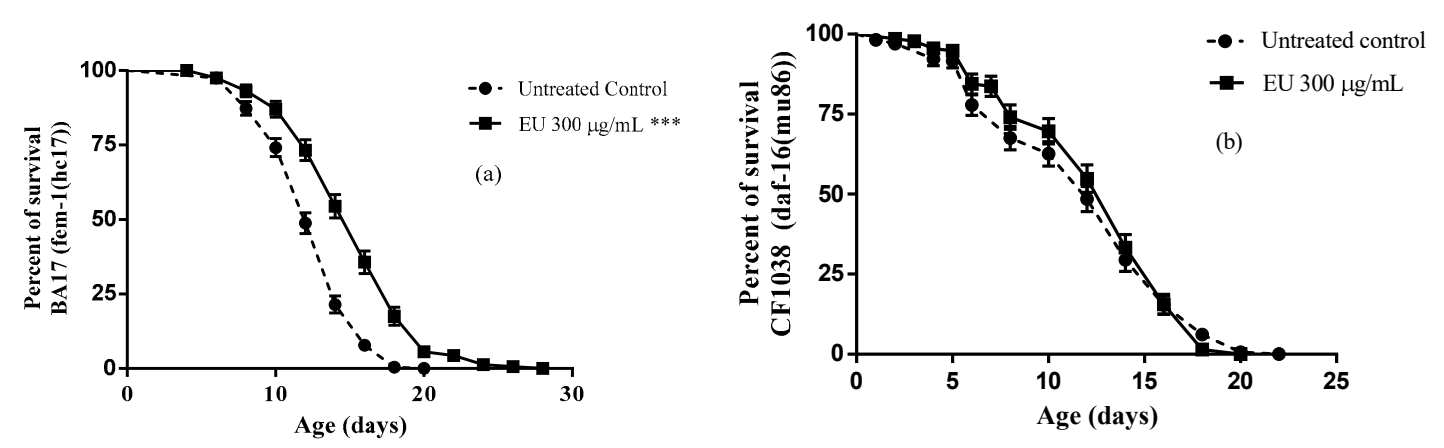

Figure 5. Longevity of C. elegans after treatment with Endopleura uchi extract (EU). BA17 worms treated with EU $300 \mu \mathrm{g} / \mathrm{mL}$ presented significantly longer lifespan compared to untreated control group (a). However, lifespan of daf-16 null mutants (CF1038) were no significantly different between EU treated and untreated worms $(\mathbf{b})$. The results are presented as percentage of surviving worms and the statistical significance determined by Log-rank (Mantel-Cox) tests followed by Gehan-Breslow-Wilcoxon Test. Note: ${ }^{* * *} p<0.001$.

\subsection{Body Length}

Body length is an important measurement to evaluate the possible deleterious effect of DR in C. elegans. In the current study, the body length of adult wild type (N2 (wt)) worms was compared between those who had been under EU treatment and the untreated ones. The data obtained indicated no differences between the groups. The treatment group had a length of $1.339 \pm 0.018 \mathrm{~mm}$ as compared to controls with of $1.261 \pm 0.018 \mathrm{~mm}$. The result indicates that the worms did not undergo caloric restriction or any toxic effect able to impair body development while treated with EU extract. 


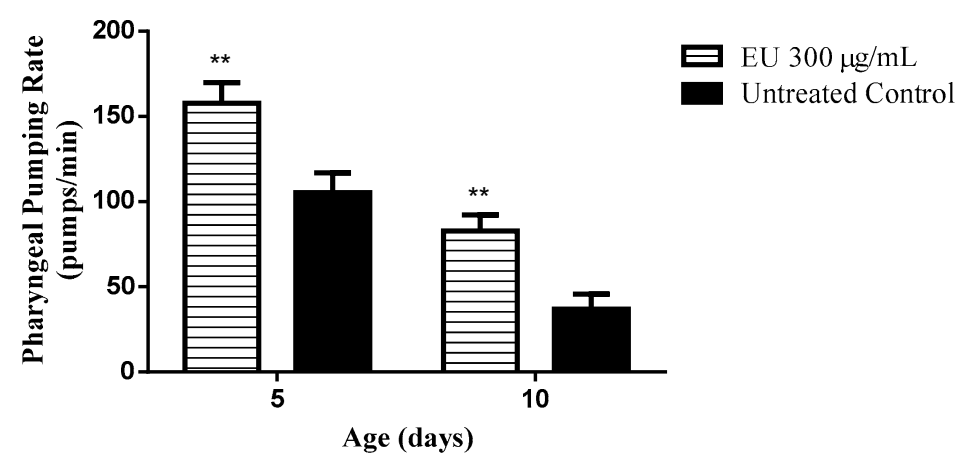

Figure 6. Pharyngeal pumping rate in C. elegans after treatment with the bark extract (EU). The treatment of wild type worms with EU $300 \mu \mathrm{g} / \mathrm{mL}$ significantly attenuated the age-associated decline in the muscle function of pharynx. Data are presented as mean $\pm \mathrm{SEM}$. Note: ${ }^{* *} p<0.01$ related to the control by a two-way ANOVA.

\subsection{Antimicrobial Activity}

The bark extract was tested against E. coli OP50, bacterial strains used to feed C. elegans, and no bactericidal effect from EU was observed (Table 2). This finding further indicates that the worms did not undergo caloric restriction during the treatment due to a reduction of food source.

Table 2. Antimicrobial activity of the Endopleura uchi (EU) bark extract assessed by well diffusion test.

\begin{tabular}{cccc}
\hline & Ampicillin $(256 \mu \mathrm{g} / \mathrm{mL})$ & Ciprofloxacin $(256 \mu \mathrm{g} / \mathrm{mL})$ & EU (10 mg/mL) \\
\hline E. coli OP50 & $27.3 \pm 1.2 *$ & $42.8 \pm 0.3 *$ & NI \\
\hline \multicolumn{4}{c}{ * Zone of inhibition (mm); NI: no inhibition. }
\end{tabular}

\subsection{Effect of the Bark Extract on the Formation of polyQ40 Aggregates}

In Huntington's disease, the disease-causing Huntington gene is mutated and carries many glutamate repeats. The formation of polyQ40 aggregates was assessed in AM141 mutants, which produce polyQ fused with GFP. The results obtained indicated a significant lower number of polyQ40::GFP aggregates among EU treated worms. At the highest tested concentration, $300 \mu \mathrm{g} / \mathrm{mL}$ $\mathrm{EU}$, the number of fluorescent aggregates scored was reduced by $60 \%$ when compared with the untreated control group (adjusted $p$-value $<0.0001$; Figure 7).

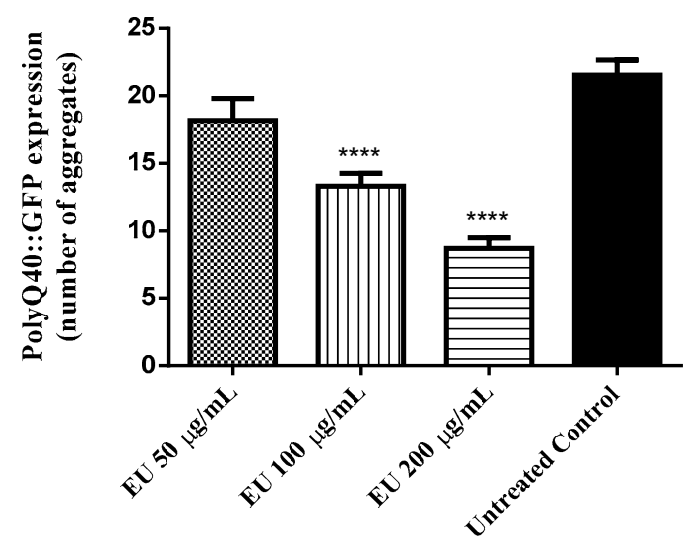

Figure 7. PolyQ40::GFP aggregate formation in mutant worms (AM141) after treatment with Endopleura uchi extract (EU). Worms treated with EU exhibited significant lower number of polyQ40::GFP aggregates compared to the control group. Data are presented as mean \pm SEM. Note: ${ }^{* * *} p<0.001$ related to the control by a one-way ANOVA followed by Bonferroni (post-hoc). 


\section{Discussion}

The Folin-Ciocalteu assay indicated a high phenolic content in EU water extract. HPLC UV/VIS analyses of our extract identified the phenolic bergenin as a major component, in line with the literature $[17,19]$. Bergenin has been reported as an antioxidant, anti-HIV, gastroprotective, neuroprotective, hepatoprotective, and immunomodulatory agent [25-29], effects that could explain the traditional uses of the barks of uxi by the locals in Amazonia.

The high antioxidant activity in vitro was also observed in vivo using C. elegans as a model organism. Notably, wild type worms treated with EU exhibited a higher survival rate after induced oxidative stress as compared to untreated worms submitted to identical conditions. These data demonstrate the capacity of the extract to counteract oxidative damage promoted by exogenous sources such as the pro-oxidant juglone [30]. In agreement, in EU treated worms we found lower accumulation of endogenous cellular ROS and lower pattern of expression for $h s p-16.2$, the gene that codes for HSP-16.2, a small heat shock protein whose expression is induced in response to harsh cellular conditions such as heat stress and oxidative damage [31,32].

Polyphenolic rich extracts are proposed to enhance cellular stress resistance through modulation of stress response genes in addition to free radical scavenging activities [33]. In the current study, sod-3, the gene coding for the mitochondrial antioxidant enzyme superoxide dismutase 3 , showed higher expression among worms treated with EU. The upregulation of sod-3 suggests the participation of the transcription factor DAF-16, the C. elegans orthologue for the mammalian FOXO transcription factor, whose target genes are mainly involved in stress resistance, metabolism, and longevity [34,35]. When testing EU in DAF-16 null mutants (CF1038 and GR1307 strains), we noticed that the protecting effect of the extract, previously demonstrated in wild type worms submitted to the survival assay, was absent. The data, therefore, confirms the requirement of DAF-16 transcription factor to promote the antioxidant effect of EU.

Plant extracts with a high content of polyphenolic compounds, such as those obtained from Camellia sinensis, Calycophyllum spruceanum, and Paullinia cupana, have been shown to extend lifespan in C. elegans due to their capacity to modulate molecular mechanisms that drive cellular stress resistance and metabolism, in line with the free radical theory of aging $[22,23,36]$. Considering the pronounced in vivo antioxidant activity of EU elicited by its capacity to modulate stress response genes in DAF-16 pathway, we also investigated whether this extract could affect longevity in C. elegans and have found a positive result. The mean lifespan of the EU treated worms was increased by $33 \%$, an effect that was absent in DAF-16 null mutants, indicating a molecular basis underlying it.

However, lifespan extension is not essentially followed by an extension of healthspan, the period of life free from diseases. The fundamental mechanisms underlying both are distinct and complex. Authors highlight that the sole extension of lifespan might not be desirable if it represents just an extended period of frailty, where individuals are vulnerable to aging-related diseases $[37,38]$.

In literature, the role of oxidative stress on the onset of aging-related diseases is well documented, thus several antioxidant compounds are claimed to be capable of attenuating or preventing the impact of aging [39]. In agreement, we obtained evidence for an anti-aging effect of EU in C. elegans by studying its muscle function, which works as marker of aging [40,41]. Analyzing the results, we observed a higher contraction rate among worms treated with the extract at all scored timepoints. This data indicates that the treatment can attenuate the age-related muscle function decline, which is considered one important aspect of the healthspan to be maintained to achieve the so-called successful aging [42].

Caloric restriction is a well-known pro-longevity stimulus [43]. To investigate whether the worms could have faced caloric restriction during the period when they were under treatment, we tested the extract against E. coli OP50 and did not find a bactericidal effect. Moreover, the pharyngeal contractile capacity of the treated worms was higher as compared to untreated worms, and when we measured the body length we found no differences between treated and untreated worms. The data indicate that 
the worms did not starve at any timepoint of their lifespan. Thus, we assume that EU can effectively extend lifespan in C. elegans by molecular mechanisms other than caloric restriction.

Neurodegenerative diseases are more prevalent in elderly and dramatically impair life quality. In this context, we decided to treat mutant worms expressing polyQ40, an expanded series of glutamine residues involved in the pathophysiology of Huntington's disease [44,45]. Our data indicate that EU treatment is able to attenuate the formation of polyQ40 aggregates, another result supporting the anti-aging properties of EU which needs to be studied in more detail.

In conclusion, the polyphenol-rich water extract from the stem bark of Endopleura uchi exhibited substantial antioxidant activity in vitro and in vivo. The extract was able to enhance the stress resistance in C. elegans through the modulation of the DAF-16/FOXO pathway. Additionally, the extract exhibited anti-aging properties being able to extend lifespan and to attenuate markers of aging, such as age-related muscle function decline and the formation of polyQ40 aggregates. Considering the traditional application of the bark of uxi and its extensive use by the local population, more studies are needed to elucidate the biological activities as well as its toxicological profile in detail.

Author Contributions: H.P. and M.R. were responsible for designing and performing the methods, analyzing data and writing the manuscript. M.B. was responsible for testing the antimicrobial properties of the extract. E.S. and K.V. were responsible for identifying and quantifying bergenin in the extract. X.W. participated in the correction and formatting of the manuscript. M.W. was the supervisor of this work, corrected data analyses and the manuscript.

Funding: This work was supported by the Brazilian National Counsel of Technological and Scientific Development $(\mathrm{CNPq})$ through the program Science Without Borders (CsF). The authors received financial support from the Deutsche Forschungsgemeinschaft and Ruprecht-Karls-Universität Heidelberg within the funding program Open Access Publishing.

Conflicts of Interest: The authors declare no conflict of interest.

\section{References}

1. Food and Fruit-Bearing Forest Species, 3: Examples from Latin America/F2911; Food and Agriculture Organization: Rome, Italy, 1986; p. 44.

2. Shanley, P. Fruit Trees and Useful Plants in Amazonian Life; Food and Agriculture Organization of the United Nations (FAO): Rome, Italy, 2011.

3. Correa, M.; Penna, L.d.A. Dicionario das plantas uteis do Brasil e das exoticas cultivadas: Volume 5. MR. Rio de Janeiro: Instituto Brasiliero de Desenvolvimento Florestal 687p.-illus. Por Icones. Geog 1974, 4.

4. Rodrigues, E. Plants and animals utilized as medicines in the Jaú National Park (JNP), Brazilian Amazon. Phytother. Res. 2006, 20, 378-391. [CrossRef] [PubMed]

5. Scudeller, V.V.; Veiga, J.B.d.; Araújo-Jorge, L.d. Etnoconhecimento de plantas de uso medicinal nas comunidades São João do Tupé e Central (Reserva de Desenvolvimento Sustentável do Tupé); UEA: Manaus, Brazil, 2009; pp. $185-199$.

6. Pinto, A.Z.d.L.; De Assis, A.F.S.; Pereira, A.G.; Pasa, M.C. Levantamento etnobotânico de plantas medicinais comercializadas no mercado do porto em Cuiabá, Mato Grosso, Brasil. FLOVET-Boletim do Grupo de Pesquisa da Flora, Vegetação e Etnobotânica 2013, 1.

7. Caetano, R.S.; de Souza, A.C.R.; Feitoza, L.F. O Uso de plantas medicinais utilizadas por frequentadores dos ambulatórios Santa Marcelina, Porto Velho-RO. Saúde e Pesquisa 2014, 7.

8. Silva, L.R.; Teixeira, R. Phenolic profile and biological potential of Endopleura uchi extracts. Asian Pac. J. Trop. Med. 2015, 8, 889-897. [CrossRef] [PubMed]

9. Bento, J.F. Caracterização de polissacarídeos e metabólicos secundários da casca de Endopleura uchi (Huber) cuatrec: Avaliação dos efeitos do decocto e de frações polissacarídicas em células hela e macrófagos. Ph.D. Thesis, Federal University of Paraná, Curitiba, PR, Brazil, November 2013.

10. Sá, B.M.; Lima, C.S.; Silva, U.D.A.; Carvalho, H.O.; Fernandes, C.P.; Resque, R.L.; de Oliveria, T.T.; Carvalho, J.C.T. Subchronic toxicity evaluation of the hydroethanolic extract from Endopleura uchi (Huber) Cuatrec in Wistar rats. Afr. J. Pharm. Pharmacol. 2015, 9, 223-229.

11. Politi, F.A.S.; Moreira, R.R.D.; Salgado, H.R.N.; Pietro, R. Preliminary tests on acute oral toxicity and intestinal motility with extract of pulverized bark of Endopleura uchi (Huber) Cuatrec. (Humiriaceae) in mice. Rev. Pan-Amaz. Saude 2010, 1, 187-189. [CrossRef] 
12. Luna, J.; Silva, T.; Bento, E.; Santana, A. Isolamento e identificação estrutural dos constituintes químicos de Endopleura uchi (Humiriaceae). Reunião Anual da Sociedade Brasileira de Química, Minas Gerais, Brasil 2000, $2,123$.

13. Politi, F.A.S. Estudos farmacognósticos e avaliação de atividades biológicas de extratos obtidos das cascas pulverizadas de Endopleura uchi (Huber) Cuatrec. (Humiriaceae). Master's Thesis, Universidade Estadual Paulista, Araraquara, SP, Brazil, February 2009.

14. Abreu, V.G.d.C.; Corrêa, G.M.; Lagos, I.A.d.S.; Silva, R.R.; Alcântara, A.F.d.C. Pentacyclic triterpenes and steroids from the stem bark of uchi (Sacoglottis uchi, Humiriaceae). Acta Amazonica 2013, 43, 525-528. [CrossRef]

15. De Abreu, H.A.; Lago, I.A.d.S.; Souza, G.P.; Piló-Veloso, D.; Duarte, H.A.; Alcântara, A.F.d.C. Antioxidant activity of (+)-bergenin-a phytoconstituent isolated from the bark of Sacoglottis uchi Huber (Humireaceae). Org. Biomol. Chem. 2008, 6, 2713-2718. [CrossRef] [PubMed]

16. Borges, J.C.; Ripardo Filho, H.d.S.; Guilhon, G.; Carvalho, J.C.; Santos, L.S.; Sousa, P.J. Antinociceptive activity of acetylbergenin in mice. Lat. Am. J. Pharm. 2011, 30, 1303-1308.

17. Tacon, L.A.; Freitas, L.A. Box-Behnken design to study the bergenin content and antioxidant activity of Endopleura uchi bark extracts obtained by dynamic maceration. Revista Brasileira de Farmacognosia 2013, 23, 65-71. [CrossRef]

18. Blois, M.S. Antioxidant determinations by the use of a stable free radical. Nature 1958. [CrossRef]

19. Nunomura, R.; Oliveira, V.G.; Da Silva, S.L.; Nunomura, S.M. Characterization of bergenin in Endopleura uchi bark and its anti-inflammatory activity. J. Braz. Chem. Soc. 2009, 20, 1060-1064. [CrossRef]

20. Peixoto, H.; Roxo, M.; Krstin, S.; Röhrig, T.; Richling, E.; Wink, M. An anthocyanin-rich extract of acai (Euterpe precatoria Mart.) increases stress resistance and retards aging-related markers in Caenorhabditis elegans. J. Agric. Food Chem. 2016, 64, 1283-1290. [CrossRef] [PubMed]

21. Stiernagle, T. Maintenance of C. elegans. WormBook 2005. [CrossRef] [PubMed]

22. Peixoto, H.; Roxo, M.; Röhrig, T.; Richling, E.; Wang, X.; Wink, M. Anti-Aging and antioxidant potential of Paullinia cupana var. sorbilis: Findings in Caenorhabditis elegans indicate a new utilization for roasted seeds of Guarana. Medicines 2017, 4, 61. [CrossRef] [PubMed]

23. Peixoto, H.; Roxo, M.; Koolen, H.; da Silva, F.; Silva, E.; Braun, M.S.; Wang, X.; Wink, M.J.M. Calycophyllum spruceanum (Benth.), the amazonian "tree of youth" prolongs longevity and enhances stress resistance in Caenorhabditis elegans. Molecules 2018, 23, 534. [CrossRef] [PubMed]

24. Ashour, M.L.; El-Readi, M.Z.; Hamoud, R.; Eid, S.Y.; El Ahmady, S.H.; Nibret, E.; Herrmann, F.; Youns, M.; Tahrani, A.; Kaufmann, D. Anti-infective and cytotoxic properties of Bupleurum marginatum. Chin. Med. 2014, 9, 1-10. [CrossRef] [PubMed]

25. Piacente, S.; Pizza, C.; De Tommasi, N.; Mahmood, N. Constituents of Ardisia japonica and their in vitro anti-HIV activity. J. Nat. Prod. 1996, 59, 565-569. [CrossRef] [PubMed]

26. Goel, R.; Maiti, R.; Manickam, M.; Ray, A. Antiulcer activity of naturally occurring pyrano-coumarin and isocoumarins and their effect on prostanoid synthesis using human colonic mucosa. Ind. J. Exp. Biol. 1997, 35, 1080-1083.

27. Takahashi, H.; Kosaka, M.; Watanabe, Y.; Nakade, K.; Fukuyama, Y. Synthesis and neuroprotective activity of bergenin derivatives with antioxidant activity. Bioorg. Med. Chem. 2003, 11, 1781-1788. [CrossRef]

28. Lim, H.-K.; Kim, H.-S.; Choi, H.-S.; Oh, S.; Choi, J. Hepatoprotective effects of bergenin, a major constituent of Mallotus japonicus, on carbon tetrachloride-intoxicated rats. J. Ethnopharmacol. 2000, 72, 469-474. [CrossRef]

29. Nazir, N.; Koul, S.; Qurishi, M.A.; Taneja, S.C.; Ahmad, S.F.; Bani, S.; Qazi, G.N. Immunomodulatory effect of bergenin and norbergenin against adjuvant-induced arthritis-A flow cytometric study. J. Ethnopharmacol. 2007, 112, 401-405. [CrossRef] [PubMed]

30. Aithal, B.K.; Kumar, M.S.; Rao, B.N.; Udupa, N.; Rao, B.S. Juglone, a naphthoquinone from walnut, exerts cytotoxic and genotoxic effects against cultured melanoma tumor cells. Cell Biol. Int. 2009, 33, 1039-1049. [CrossRef] [PubMed]

31. Strayer, A.; Wu, Z.; Christen, Y.; Link, C.D.; Luo, Y. Expression of the small heat-shock protein HSP 16-2 in Caenorhabditis elegans is suppressed by Ginkgo biloba extract EGb 761. FASEB J. 2003, 17, 2305-2307. [CrossRef] [PubMed]

32. Swindell, W.R. Heat shock proteins in long-lived worms and mice with insulin/insulin-like signaling mutations. Aging 2009, 1, 573. [CrossRef] [PubMed] 
33. Scalbert, A.; Johnson, I.T.; Saltmarsh, M. Polyphenols: Antioxidants and beyond. Am. J. Clin. Nutr. 2005, 81, 215-217. [CrossRef] [PubMed]

34. Braeckman, B.P.; Vanfleteren, J.R. Genetic control of longevity in C. elegans. Exp. Gerontol. 2007, 42, 90-98. [CrossRef] [PubMed]

35. Mukhopadhyay, A.; Oh, S.W.; Tissenbaum, H.A. Worming pathways to and from DAF-16/FOXO. Exp. Gerontol. 2006, 41, 928-934. [CrossRef] [PubMed]

36. Abbas, S.; Wink, M. Epigallocatechin gallate from green tea (Camellia sinensis) increases lifespan and stress resistance in Caenorhabditis elegans. Planta Med. 2009, 75, 216-221. [CrossRef] [PubMed]

37. Hansen, M.; Kennedy, B.K. Does longer lifespan mean longer healthspan? Trends Cell Biol. 2016, 26, 565-568. [CrossRef] [PubMed]

38. Bansal, A.; Zhu, L.J.; Yen, K.; Tissenbaum, H.A. Uncoupling lifespan and healthspan in Caenorhabditis elegans longevity mutants. Proc. Natl. Acad. Sci. USA 2015, 112, 277-286. [CrossRef] [PubMed]

39. Cui, H.; Kong, Y.; Zhang, H. Oxidative stress, mitochondrial dysfunction, and aging. J. Signal Transduct. 2011, 2012. [CrossRef] [PubMed]

40. Peixoto, H.; Roxo, M.; Krstin, S.; Wang, X.; Wink, M. Anthocyanin-rich extract of Acai (Euterpe precatoria Mart.) mediates neuroprotective activities in Caenorhabditis elegans. J. Funct. Foods 2016, 26, 385-393. [CrossRef]

41. Collins, J.J.; Huang, C.; Hughes, S.; Kornfeld, K. The measurement and analysis of age-related changes in Caenorhabditis elegans. WormBook 2005. [CrossRef]

42. Anton, S.D.; Woods, A.J.; Ashizawa, T.; Barb, D.; Buford, T.W.; Carter, C.S.; Clark, D.J.; Cohen, R.A.; Corbett, D.B.; Cruz-Almeida, Y.; et al. Successful aging: Advancing the science of physical independence in older adults. Ageing Res. Rev. 2015, 24, 304-327. [CrossRef] [PubMed]

43. Fontana, L.; Partridge, L.; Longo, V.D. Extending healthy life span—from yeast to humans. Science 2010, 328, 321-326. [CrossRef] [PubMed]

44. Finkbeiner, S. Huntington's disease. Cold Spring Harb Perspect. Biol. 2011, 3, 7476. [CrossRef] [PubMed]

45. Cohen, E.; Dillin, A. The insulin paradox: Aging, proteotoxicity and neurodegeneration. Nat. Rev. Neurosci. 2008, 9, 759-767. [CrossRef] [PubMed]

Sample Availability: Samples of the compounds are available from the authors.

(C) 2019 by the authors. Licensee MDPI, Basel, Switzerland. This article is an open access article distributed under the terms and conditions of the Creative Commons Attribution (CC BY) license (http://creativecommons.org/licenses/by/4.0/). 